\title{
Examining the Role of Implicit and Explicit L2 Knowledge in General L2 Proficiency
}

\author{
Runhan Zhang ${ }^{1}$ \\ ${ }^{1}$ School of Foreign Studies, Central University of Finance and Economics, Beijing, China \\ Correspondence: Runhan Zhang, School of Foreign Studies, Central University of Finance and Economics, \\ Beijing, China. E-mail: zhangrunhan_nora@hotmail.com
}

Received: April 3, 2015 Accepted: April 21, $2015 \quad$ Online Published: May 30, 2015

doi:10.5539/ijel.v5n3p79 URL: http://dx.doi.org/10.5539/ijel.v5n3p79

\begin{abstract}
Implicit and explicit linguistic knowledge have long been at the centre of second language acquisition research, whereas language proficiency is often examined in language testing. Viewing language proficiency in terms of implicit and explicit linguistic knowledge would provide helpful insight to bridging the two fields. However, very few empirical studies have focused on the relationship between these two types of knowledge and general language proficiency except Elder and Ellis (2009). The results of Elder and Ellis (2009) indicated that language proficiency can be conceptualized as involving both types of knowledge with explicit knowledge of a second language (L2) being a stronger predictor of general L2 proficiency. Likewise, all four measures used in the current study to elicit English learners' implicit and explicit knowledge of English were found to correlate significantly with the English proficiency measure in a Chinese (as opposed to English as a second language) context. Nevertheless, only the two measures of implicit knowledge were found to predict the participants' general English proficiency score. Reasons for the difference may be attributed to several factors, including the use of different proficiency tests and the adoption of slightly different statistical analysis methods.
\end{abstract}

Keywords: implicit L2 knowledge, explicit L2 knowledge, general L2 proficiency, relationship

\section{Introduction}

Implicit and explicit linguistic knowledge are at the heart of second language acquisition. It is agreed that implicit linguistic knowledge refers to "knowledge of language that is intuitive and procedural" (Zhang, 2014, p.1), whereas explicit linguistic knowledge refers to "knowledge about language" (Zhang, 2014, p.1). Defining language proficiency theoretically, on the other hand, is often a contentious issue; researchers and practitioners holding different positions never agree on its definition. In Oller and Damico's (1991) opinion, the nature and specification of the elements of language proficiency have not been determined; therefore, the debate on the definition continues among academicians and practitioners. Thomas (1994) provides a general definition of second language proficiency. According to Thomas (1994), second language proficiency indicates "a person's overall competence and ability to perform in L2 [second language]" (p. 330). Grammar is considered to be one of the major components of second language proficiency. Due to the lack of valid and reliable measures of implicit and explicit L2 knowledge, previous studies examining the relationship between explicit L2 knowledge and L2 proficiency have demonstrated mixed results (e.g., Sorace, 1985; Alderson, Clapham, \& Steel, 1997; Renou, 2001; White \& Ranta, 2002; Hu, 2002; Elder \& Manwaring, 2004; Roehr, 2008) . In the meantime, the relationship between implicit L2 knowledge and L2 proficiency still remains a blank. Thus, the role of implicit/explicit L2 knowledge in general L2 proficiency needs more empirical examination.

\section{Review of Studies Examining the Role of Implicit and Explicit Knowledge in General Language Proficiency}

As is mentioned above, very few empirical studies have focused on investigating the relationship between implicit/explicit knowledge and general L2 proficiency. Therefore, two studies whose main purpose was to examine the relationship between implicit/explicit L2 knowledge and general L2 proficiency will be reviewed: Han and Ellis (1998) and Elder and Ellis (2009).

Han and Ellis (1998) focused their attention on probing the relationship between implicit/explicit L2 knowledge and general L2 proficiency among 48 adult English learners, who enrolled in two summer sessions of an 
American university intensive English language programme in the United States. The participants' scores of two language proficiency tests-TOEFL (Test of English as a Foreign Language) and SLEP (Secondary Level Proficiency Test) were collected. The TOEFL test contained three sections: (1) Listening Comprehension, (2) Structure and Written Expression, and (3) Vocabulary and Reading Comprehension. The SLEP test contained two sections: Listening Comprehension and Reading Comprehension. Additionally, four measures of implicit and explicit knowledge, including scores on the Oral Productive Test (OPT), Timed Grammaticality Judgment Test (TGJT), Delayed Grammaticality Judgment Test (Delayed GJT) and Metalingual Comments were also obtained. The target grammatical structure investigated was "verb complement." Pearson product moment correlations were calculated. The results revealed that the SLEP test moderately correlated with the OPT, TGJT, and Delayed GJT ( $\mathrm{r}=.47, .49$, and .43$)$, reflecting that this proficiency test appeared to tap both implicit and explicit knowledge. Nevertheless, scores on the TOEFL correlated only moderately with the Delayed GJT $(\mathrm{r}=.49)$, indicating that it appeared to tap primarily explicit knowledge. The results demonstrated that both implicit and explicit L2 knowledge might play a role in general L2 proficiency, which lends support to Bialystok's (1982) claim that language proficiency is made up of unanalysed and analysed knowledge. However, the Metalingual Comments were not found to significantly relate to either measure of general L2 proficiency, suggesting that metalinguistic knowledge does not play a significant role in general L2 proficiency, while analysed explicit knowledge does.

Elder and Ellis (2009) later conducted a study aiming to explore the extent to which implicit and explicit L2 knowledge predict L2 proficiency scores. Two sub-studies were involved. Sub-study 1 examined the relationship between measures of implicit and explicit L2 knowledge of 17 grammatical structures (Ellis, 2005) and the measure of language proficiency (TOEFL); sub-study 2 aimed to investigate the extent to which implicit and explicit L2 knowledge of specific grammatical features related to general L2 proficiency. In sub-study 1, participants were 111 students enrolled either in professional English classes or in tertiary academic courses in New Zealand. Three tests measuring implicit/explicit L2 knowledge were employed in the study, including the TGJT, UGJT, and MKT. The participants' scores on two versions of the TOEFL test (Computer-based TOEFL [TOEFL CBT] and internet-based TOEFL [TOEFL iBT]) were collected. The learner scores on all the tests were analysed by running a principal components analysis with varimax rotation and a forced two-factor solution. All parts of the TOEFL CBT and the TOEFL iBT (i.e., Writing, Reading and Listening on the CBT/iBT, and the CBT Structure and iBT Speaking) loaded strongly on Component 1 (.66 or higher), while very weak loadings (.24 or lower) were found between these parts on Component 2. The results indicated that the relationship between general L2 proficiency as measured by both versions of the TOEFL test and implicit knowledge was extremely weak, whereas the relationship between explicit knowledge and general L2 proficiency was quite strong. One explanation for the stronger role played by explicit knowledge in predicting language proficiency is that the tests used in the study did not elicit "unanalysed automated language" (Elder \& Ellis, 2009, p.178). Given these results, it should be admitted that the relationship between implicit knowledge and language proficiency is far from conclusive. Therefore, it was encouraged that the Elicited Imitation Test (EIT), which was not used in the study and has been shown to be the best measure of implicit knowledge, should be used in future research.

Sub-study 2 involved 50 learners in foundation courses or in courses in private language schools in New Zealand. The same 17 grammatical structures used in sub-study 1 were employed in this sub-study. Four measures were used to measure the participants' implicit and explicit linguistic knowledge, including the EIT, TGJT, UGJT, and MKT. Participants' scores from the IELTS test measuring their L2 proficiency were also obtained. A key finding in this sub-study was that the implicit and explicit measures of the same structure were not both related to proficiency. The results of a series of correlation and multiple regression analyses also displayed that the measures of both implicit and explicit knowledge predicted IELTS Total scores. Implicit knowledge was found to be a significant predictor of both Speaking and Writing, whereas explicit knowledge predicted both Listening and Reading.

In summary, although the findings of the reviewed studies lent support to viewing general L2 proficiency in terms of implicit and explicit L2 knowledge (Elder \& Ellis, 2009), they only afforded limited empirical support for it. So the relationship between implicit/explicit L2 knowledge and general L2 proficiency still needs further empirical investigation.

\section{The Current Study}

The current study was designed to examine the role of implicit and explicit L2 knowledge in general L2 proficiency in an EFL context (mainland China). L2 was English in this study. The study was conducted at a key university in Beijing. A total of 49 English majors participated in the current study. The majority of the 
participants were female $(n=43)$. Four of the tests used in Ellis $(2005,2009)$ were employed to measure the participants' implicit and explicit grammatical knowledge, namely the EIT (See Appendix A), TGJT (See Appendix B), UGJT UG (only the ungrammatical items were used in the current study because the ungrammatical items were proved as a better measure of explicit knowledge (see Appendix C), and MKT (see Appendix D). The former two tests were intended to elicit the participants' implicit L2 knowledge, while the latter tended to elicit the participants' explicit L2 knowledge. The target structures of the measures were the same 17 grammatical structures as those used in Ellis $(2005,2009)$. These four tests were also validated as measures of implicit and explicit L2 knowledge in an EFL context (see details in Zhang, 2014). The Oxford Placement Test (OPT; see Appendix E) as a standardized proficiency test was used to measure participants' general L2 proficiency. The OPT is comprised of two sections - a Listening Test and a Grammar Test, each consisting of 100 items. It took 60 minutes to complete the two sections (10 minutes for the listening part and 50 minutes for the grammar part). The total score was 200 (100 for each section and 1 for each item). The Listening Test required the learners to choose a correct answer from two possibilities in each item immediately after listening to the item, while the Grammar Test was a written multiple-choice test of the grammatical structure of English. In this section, the students were asked to choose the correct answer from three possibilities given for each sentence. Two specific research questions guided the current study:

1) What is the role of Chinese first year university students' implicit L2 knowledge in their general L2 proficiency?

2) What is the role of Chinese first year university students' explicit L2 knowledge in their general L2 proficiency?

\section{Results}

A series of statistical analyses were carried out to investigate the reliability of the four measures and the role that implicit/explicit L2 knowledge plays in L2 proficiency. Table 1 shows the reliability coefficient for each of the four tests. According to DeVellis (1991), Cronbach's alpha values ranging from .65 to .70 indicate acceptable reliability, whereas values from .70 to .80 indicate fairly good reliability (i.e., very good consistency). As seen in Table 1, all alphas for all tests had good reliability for this learner population ( $>.65)$. Table 2 shows the mean and standard deviations of scores on the four tests of implicit and explicit L2 knowledge, as well as their proficiency test including the Listening Test and the Grammar Test. It can be seen that the participants scored highest on the UGJT UG $(M=.88)$, followed by the MKT $(M=.55)$, and then the TGJT $(M=.52)$. They achieved the lowest scores on the EIT $(M=.45)$.

Table 1 . Reliability values of the tests $(n=49)$

\begin{tabular}{lll}
\hline Tests & Items & Reliability $(\alpha)$ \\
\hline EIT & 34 & .82 \\
TGJT & 68 & .68 \\
UGJT & 34 & .69 \\
MKT & 40 & .75 \\
\hline
\end{tabular}

Note. EIT $=$ elicited imitation test; TGJT = timed grammaticality judgment test;

UGJT UG = untimed grammaticality judgment test ungrammatical items; MKT = metalinguistic knowledge test.

Table 2. Descriptive statistics of the tests $(\mathrm{n}=49)$

\begin{tabular}{llll}
\hline Tests & Items & Mean & SD \\
\hline EIT & 34 & .45 & .14 \\
TGJT & 68 & .52 & .10 \\
UGJTUG & 34 & .88 & .09 \\
MKT & 40 & .55 & .12 \\
\hline Proficiency & 200 & .69 & .05 \\
Proficiency L & 100 & .66 & .07 \\
Proficiency G & 100 & .72 & .08 \\
\hline
\end{tabular}

Note . EIT $=$ elicited imitation test; TGJT $=$ timed grammaticality judgment test $=$ UGJT UG $=$ untimed grammaticality judgment test ungrammatical items; MKT = metalinguistic knowledge test; Proficiency $=$ The Oxford Placement Test; Proficiency L $=$ The Oxford Placement Test Listening Part; Proficiency G = The Oxford Placement Test Grammar Part. 
A Pearson product moment correlation was then conducted to examine the relationship between the measures of implicit/explicit knowledge and L2 proficiency test and its sub-tests. Table 3 displays the results. It can be seen from Table 3 that the participants' scores on all measures of L2 knowledge correlated significantly with their scores on the general L2 proficiency test and the grammar part. However, it was interesting to find that only the participants' scores on the two measures of implicit L2 knowledge correlated significantly with their scores on the proficiency listening part.

Table 3. Correlations among the Four Tests and L2 Proficiency $(n=49)$

\begin{tabular}{lllll}
\hline & EIT & TGJT & UGJT UG & MKT \\
\hline Proficiency & $.581^{* *}$ & $.535^{* *}$ & $.446^{* *}$ & $.410^{* *}$ \\
Proficiency L & $.287^{*}$ & $.344^{*}$ & .161 & .105 \\
Proficiency G & $.577^{* *}$ & $.472^{* *}$ & $.489^{* *}$ & $.496^{* *}$ \\
\hline
\end{tabular}

Note. EIT $=$ elicited imitation test; TGJT $=$ timed grammaticality judgment test $=$ UGJT UG $=$ untimed grammaticality judgment test ungrammatical items; MKT $=$ metalinguistic knowledge test; Proficiency $=$ The Oxford Placement Test; Proficiency L=The Oxford Placement Test Listening Part; Proficiency G= The Oxford Placement Test Grammar Part.

$* * \mathrm{p}<.01$

$* \mathrm{p}<.05$

Based on the results from the correlation analysis, three stepwise multiple regression analyses were carried out to further examine the relationships between implicit/explicit L2 knowledge and general L2 proficiency, the proficiency grammar part, and the proficiency listening part. These were also intended to investigate whether the participants' scores on implicit and explicit L2 knowledge predicted their scores on their L2 proficiency and its separate parts. For the first multiple regression analysis, the OPT was the dependent variable, while the measures of implicit and explicit L2 knowledge were the independent variables. Table 4 shows the results. The scores on the EIT and TGJT were found to predict the scores of general L2 proficiency $(\mathrm{F}=18.541, \mathrm{p}=.000<.05)$. The value for the multiple $R$ was .668 . $R$ Square $\left(R^{2}\right)$ indicates the proportion of the variance in the dependent variable that is accounted for by this model. However, it "tends to somewhat over-estimate the success of the model when applied to the real world, so an Adjusted R Square value is calculated which takes into account the number of variables in the model and the number of observations (participants) our model is based on" (Brace, Kemp, \& Snelgar, 2006, p. 209). Consequently, the adjusted $\mathrm{R}^{2}$ in Table 4 reveals that EIT and TGJT made up $42.2 \%$ of the variance in the general L2 proficiency scores in this sample. It also demonstrates the respective beta values of these two measures. "Beta value is a measure of how strongly each predictor variable influences the dependent variable" and "the higher the beta value the greater the impact of the predictor variable on the dependent variable" (Brace, Kemp, \& Snelgar, 2006, p. 208). Therefore, the EIT was found to be a slightly better predictor of general L2 proficiency (Beta $=.437, \mathrm{p}=.001$ ) in this sample.

Table 4. Multiple regression analysis of measures of L2 knowledge and general L2 proficiency $(\mathrm{n}=49)$

\begin{tabular}{llll}
\hline Model & Beta & $\mathrm{t}$ & Sig. $(\mathrm{p})$ \\
\hline EIT & .437 & 3.646 & .001 \\
TGJT & .360 & 3.008 & .004 \\
$\mathrm{R}=.668$ & $\mathrm{R}^{2}=.446$ & Adjusted $\mathrm{R}^{2}=.422$ & $\mathrm{~F}=18.541$ \\
& & & Sig. $=.000$ \\
\hline
\end{tabular}

Note. Method: Stepwise (Criteria: Probability-of-F-to-enter $<=.050$, Probability-of- F-to-remove $>=.100$ )

Predictors: EIT, TGJT, UGJT UG, MKT

Dependent Variable: General L2 proficiency

Table 5 presents the results of the second multiple regression analysis. The proficiency listening part was the dependent variable, while the measures of implicit and explicit L2 knowledge were the independent variables. Table 5 indicates that only the participants' score on the TGJT predicted the score on their L2 listening proficiency $(\mathrm{F}=6.320, \mathrm{p}=.015<.05)$. The value for the multiple $\mathrm{R}$ when predicting $\mathrm{L} 2$ listening proficiency from the TGJT was .344. The adjusted $\mathrm{R}^{2}$ shows that the TGJT accounted for $11.4 \%$ of the variance in the score on L2 listening proficiency in this sample. 
Table 5. Multiple regression analysis of measures of L2 knowledge and proficiency listening $(\mathrm{n}=49)$

\begin{tabular}{llll}
\hline Model & Beta & $\mathrm{t}$ & Sig. $(\mathrm{p})$ \\
\hline TGJT & .344 & 2.512 & .015 \\
$\mathrm{R}=.344$ & $\mathrm{R}^{2}=.118$ & Adjusted $\mathrm{R}^{2}=.100$ & $\mathrm{~F}=6.310$ Sig. $=.015$ \\
\hline
\end{tabular}

Note. Method: Stepwise (Criteria: Probability-of-F-to-enter $<=.050$, Probability-of- F-to-remove $>=.100$ )

Predictors: EIT, TGJT, UGJT UG, MKT

Dependent Variable: Proficiency Listening

Table 6 shows the results of the third multiple regression analysis. The proficiency grammar part was the dependent variable, while the measures of implicit and explicit L2 knowledge were the independent variables. It can be seen from Table 6 that the participants' scores on one measure of explicit L2 knowledge (i.e., the EIT) and two measures of implicit L2 knowledge (i.e., the UGJT UG and MKT) predicted the scores of their L2 grammatical proficiency $(\mathrm{F}=15.860, \mathrm{p}=.000<.05)$. The multiple $\mathrm{R}$ value when predicting $\mathrm{L} 2$ grammatical proficiency from these three measures was .717 . The Adjusted $\mathrm{R}^{2}$ indicates that the model consisting of these three measures accounted for $48.2 \%$ of the variance in the scores on L2 grammar in this sample.

Table 6. Multiple Regression analysis of measures of L2 knowledge and proficiency grammar ( $\mathrm{n}=49)$

\begin{tabular}{llll}
\hline Model & Beta & \multicolumn{1}{c}{$\mathrm{t}$} & Sig. $(\mathrm{p})$ \\
\hline EIT & .390 & 3.361 & .002 \\
UGJT UG & .334 & 3.077 & .004 \\
MKT & .254 & 2.190 & .004 \\
$\mathrm{R}=.717$ & $\mathrm{R}^{2}=.514$ & Adjusted $\mathrm{R}^{2}=.482$ & $\mathrm{~F}=15.860$ Sig. $=.000$ \\
\hline
\end{tabular}

Note. Method: Stepwise (Criteria: Probability-of-F-to-enter $<=.050$, Probability-of- F-to-remove $>=.100$ )

Predictors: EIT, TGJT, UGJT UG, MKT

Dependent Variable: Proficiency Grammar

\section{Discussion}

The current study examined the role of implicit and explicit L2 knowledge in general L2 proficiency. As mentioned above, the first year students' L2 proficiency was measured by the Oxford Placement Test (OPT), which is comprised of two parts: Listening and Grammar. Their implicit L2 knowledge was measured by the EIT and TGJT and their explicit L2 knowledge was measured by the UGJT UG and MKT. The overall reliability values of the four measures of implicit and explicit L2 knowledge were satisfactory. The present study focused on the participants' implicit and explicit morphosyntactic knowledge only. Accordingly, it is reasonable to hypothesize that both the two types of knowledge would correlate significantly with general L2 proficiency, particularly with the grammar score. The results of the correlation analysis reported in Table 3 confirmed this hypothesis.

Elder and Ellis (2009) found that the relationship between implicit knowledge and general L2 proficiency measured by two versions of the TOEFL test was extremely weak; however, that between explicit knowledge and proficiency was quite strong. Moreover, the measures of both implicit and explicit knowledge were found to predict general L2 proficiency score measured by the IELTS test. By comparing the results of this study with those of Elder and Ellis (2009) study, it should be noted that two studies differed in some aspects: (1) Slightly different tests were used to measure implicit L2 knowledge. Sub-study 1 of Elder and Ellis (2009) only employed one test, the TGJT, to measure implicit knowledge, while the present study used two tests to measure this construct: EIT and TGJT; (2) Different proficiency tests were employed. Elder and Ellis used the computer-based TOEFL (CBT) and the pilot version of the internet-based TOEFL (iBT) (both of which consist of Listening, Writing, and Reading parts); however, the present study employed the OPT (which is only comprised of Listening and Grammar parts); (3) Different types of statistical analyses were used. The Elder and Ellis (2009) sub-study 1 conducted a principal component analysis with varimax rotation and a forced two-factor solution of all the test components including the tests of implicit/explicit L2 knowledge and L2 proficiency (TOEFL CBT and iBT). The present study employed a Pearson correlation analysis and three multiple regression analyses. Consequently, different from Elder and Ellis (2009) study, the participants' scores on measures of implicit L2 knowledge were found to play a stronger role than those of explicit L2 knowledge in their general L2 proficiency and their listening proficiency, as shown in Tables 4 and 5. One possible explanation for the different 
results is that there was a difference in time pressure in the tests used in the two studies. The TOEFL CBT Listening contained three parts consisting of short conversations and also short texts around 100 words in length. In contrast, the TOEFL iBT Listening was made up of a number of monologic lecture-type passages and mini-conversations with between five and six questions per text. The texts were longer than on those on the TOEFL CBT. Moreover, there were opportunities for testees to take notes while listening. Even in some cases, parts of the listening tests were repeated. In contrast, the OPT Listening used for the current investigation contained 100 sentences with two word or phrase choices. It required students to tick the correct word. In other words, there was almost no interval between sentences, which meant that the participants did not have time to reflect and they were required to tick what they heard very quickly; otherwise, they would have missed the next sentence. The more intensive time pressure of the OPT Listening compared with the TOEFL CBT and iBT may explain why it only correlated with one of the implicit L2 knowledge measures.

However, it should be realized that the current study has some limitations. First, the proficiency test employed did not comprehensively test four skills-listening, speaking, reading, and writing. Second, the sample involved is relatively small. Thus, a more comprehensive proficiency test and a larger sample of participants would be suggested for future related research.

\section{Acknowledgement}

This project is funded by the School of Foreign Studies, Central University of Finance and Economics, Beijing, China.

\section{References}

Alderson, J. C., Clapham, C., \& Steel, D. (1997). Metalinguistic knowledge, language aptitude and language proficiency. Language Teaching Research, 1, 93-121. http://dx.doi.org/10.1177/136216889700100202

Bialystok, E. (1982). On the relationship between knowing and using forms. Applied Linguistics, 3, 181-206. http://dx.doi.org/10.1093/applin/3.3.181

Brace, N., Kemp, R., \& Sneglar, R. (2006). SPSS for sychologists. London: Psychology Press.

DeVellis, R. F. (1991). Scale development. Newbury Park, NJ: Sage Publications.

Elder, C., \& Ellis , R. (2009). Implicit and explicit knowledge of an L2 and language proficiency. In R. Ellis et al. (Eds.), Implicit and Explicit Knowledge in Second Language Learning, Testing and Teaching (pp. 167-193). Bristol, Buffalo and Toronto: Multilingual Matters.

Elder, C., \& Manwaring, D. (2004). The relationship between met linguistic knowledge and learning outcomes among undergraduate students of Chinese. Language Awareness, 13, 145-162. http://dx.doi.org/10.1080/09658410408667092

Ellis, R. (2005). Measuring implicit and explicit knowledge of a second language: Apsychometric study. Studies in Second Language Acquisition, 27, 141-172. http://dx.doi.org/10.1017/s0272263105050096

Ellis, R. (2009). Measuring implicit and explicit knowledge of a second language. In R. Ellis, S. Loewen, C. Elder, R. Erlam, J. Philp, \& H. Reinders (Eds.), Implicitand explicit knowledge in second language learning, testing and teaching (pp. 31-64). Bristol, UK: Multilingual Matters.

Han, Y., \& Ellis, R. (1998). Implicit knowledge, explicit knowledge and general language proficiency. Language Teaching Research, 2, 1-23. http://dx.doi.org/10.1177/136216889800200102

$\mathrm{Hu}$, G. (2002). Psychological constraints on the utility of metalinguistic knowledge in second language production. Studies in Second Language Acquisition, 24, 347-386. http://dx.doi.org/10.1017/s0272263102003017

Oller, J. W. Jr., \& Damico, J. S. (1991). Theoretical considerations in the assessment of LEP students. In E. Hamayan \& J. S. Damico (Eds.), Limiting Bias in the Assessment of Bilingual Students (pp. 77-110). Austin, TX: Pro-Ed Publications.

Renou, J. (2001). An examination of the relationship between met linguistic awareness and second-language proficiency of adult learners of French. Language Awareness, 10, 248-267. http://dx.doi.org/10.1080/09658410108667038

Roehr, K. (2008). Metalinguistic knowledge and language ability in university-level L2 learners. Applied Linguistics, 29, 173-199. http://dx.doi.org/10.1093/applin/amm037

Sorace, A. (1985). Metalinguistic knowledge and language use in acquisition-poor environments. Applied 
Linguistics, 6, 239-254. http://dx.doi.org/10.1093/applin/6.3.239

Thomas, M. (1994). Assessment of L2 proficiency in second language acquisition research. Language Learning ,44, 307-336. http://dx.doi.org/10.1111/j.1467-1770.1994.tb01104.x

White, J., \& Ranta, L. (2002). Examining the interface between metalinguistic task performance and oral production in a second language. Language Awareness, 11, 259-290. http://dx.doi.org/10.1080/09658410208667060

Zhang, R. H. (2014). Measuring University-Level L2 Learners' Implicit and Explicit Linguistic Knowledge. Studies in Second Language Acquisition. http://dx.doi.org/10.1017/S0272263114000370

\section{Appendix A}

\section{A Representative Sample of Sentences in the EIT}

( $\mathbf{G}=$ Grammatical; $\mathbf{U G}=$ Ungrammatical $)$

\section{Comparatives}

Chinese people are nicer and more polite than other people. (G)

It is more harder to learn math than to learn chemistry. (UG)

\section{Verb Complements}

Most college students want to get high marks in their examinations. (G)

Young people usually want leaving their families as soon as possible. (UG)

\section{Adverb Placement}

People play Ping Pong well and football badly in China. (G)

Young people play often internet games and drink a lot. (UG)

\section{Appendix B}

A Representative Sample of Sentences in the Timed Grammaticality Test (G = Grammatical; UG =Ungrammatical)

Since (G): I haven't seen him for a long time.

Dative (G): The teacher explained the problem to the students.

Verb complement (UG): Liao says he wants buying a car next week.

Past -ed (UG): Martin completed his assignment and print it out.

\section{Appendix C}

\section{A Representative Sample of Ungrammatical Sentences in the Untimed Grammaticality Test}

Passive (UG) An accident was happened on the motorway.

Adverb (UG) She likes always watching television.

Dative (UG) He reported his father the bad news.

\section{Appendix D}

\section{A Representative Sample of the Sentences in the Metalinguistic Knowledge Test}

\section{Metalinguistic Knowledge Test, Part 1}

(1) You must to wash your hands before eating.

a. "Must to" is the wrong form of the imperative.

b. Change to "must have to wash" to express obligation.

c. Modal verbs should never be followed by a preposition.

d. After "must" use the base form of the verb not the infinitive. 
(2) Hiroshi wants visiting the United States this year.

a. 'visiting' should be written in the base form.

b. The verb following 'want' must be an infinitive.

c. We cannot have two verbs together in a sentence.

d. It should be 'visit' because the event is in the future.

\section{Metalinguistic Knowledge Test, Part 2}

(1) Read the passage below. Find ONE example in the passage for each of the grammatical features listed in the table. Write the examples in the table in the spaces provided. The first one is done for you. Note: it may be possible to choose the same example to illustrate more than one grammatical feature.

Passage:

The materials are delivered to the factory by a supplier, who usually has no technical knowledge, but who happens to have the right contacts. We would normally expect the materials to arrive within three days, but this time it has taken longer.

\begin{tabular}{|l|l|}
\hline Grammatical Feature & Example \\
\hline Definite article & the \\
\hline
\end{tabular}

\section{Appendix E}

A Representative Sample of Sentences in the Oxford Placement Test

Oxford Placement Test 1

\section{Listening Test}

\begin{tabular}{|l|}
\hline Name \\
Total Listening \\
Total Grammar \\
Grand Total
\end{tabular}

Look at the example below. Listen to the tape. You will hear the example once only.

Decide which word you hear, 'soap', or 'soup'.

a. Will you get some soap soup at the supermarket?

The word was 'soup', so 'soup' is ticked. Now look at these examples, and listen to the tape again. This time, you tick the words you hear. For example, if you hear 'shorts', tick 'shorts'.

a. The team need new shirts shorts.

b. They've recently developed a new kind of vine wine around here.

The words on the tape were 'shorts' and 'vine', so the correct answers look like this:

b. The team need new shirts shorts .

c. They've recently developed a new kind of vine 1 wine around here.

\section{Grammar Test PART 1}

\begin{tabular}{|lr|}
\hline Name & \\
Total Listening & $/ 100$ \\
Total Grammar & $/ 100$ \\
Grand Total & \multicolumn{1}{r}{200} \\
\hline
\end{tabular}




\section{Look at these examples. The correct answer is ticked.}

a. In warm climates people likev likes are liking sitting outside in the sun.

b. If it is very hot, they sit at in $\sqrt{\text { under the shade. }}$

Now the test will begin. Tick the correct answer.

1. Water is to boil is boiling boils at a temperature of $100^{\circ} \mathrm{C} 1$

2. In some countries there is is it is very hot all the time. 2

\section{Grammar Test Part 2}

51. Many teachers say to say tell their students should learn a foreign language. 51

52. Learning a second language is not the same as like than learning a first language. 52

\section{Copyrights}

Copyright for this article is retained by the author(s), with first publication rights granted to the journal.

This is an open-access article distributed under the terms and conditions of the Creative Commons Attribution license (http://creativecommons.org/licenses/by/3.0/). 